\title{
José Enrique Rodó y William James, ¿Un contrapunto humanístico-filosófico americano?
}

\author{
Luis Pulido Ritter ${ }^{1,2, *}$ \\ ${ }^{1}$ Universidad Libre de Berlín \\ ${ }^{2}$ Universidad de Panamá \\ *Autor para correspondencia. Email:
}

Recibido: 7 de diciembre de 2015

Aceptado: 10 de diciembre de 2015

\begin{abstract}
This text deals with comparing two texts Ariel by the Uruguayan Jose Enrique Rodo (1900) and the Pragmatism (1907) by the American William James. Through these texts, which have not been compared before, are founded american intellectuals traditions that until today have continued to be influential among intellectuals. Especially James Pragmatism is articulated in a series of texts written by Pierce and Dewey that, unlike Arielism, which quickly sold out its possibilities of reception and reproduction, has continued to interest scholars and intellectuals from around the world. The purpose of this paper is to show that there are similarities between the two ways of thinking and pragmatism, so unknown and vilified in Spanish America for being apparently an ideology of Empire and the north, it is a perfect partner to initiate a transcultural dialogue in the continent.
\end{abstract}

Keywords: Pragmatism; Arielism; America; Transcultural dialogue.

\section{Resumen}

Este texto se ocupará de comparar dos textos el Ariel del uruguayo José Enrique Rodó (1900) y el Pragmatismo (1907) del norteamericano William James. A través de estos textos, que no han sido comparados anteriormente, se fundaron tradiciones intelectuales americanas que hasta hoy día no han dejado de ser influyentes entre los intelectuales, el primero. Especialmente, el Pragmatismo de James se articula en una serie de textos escritos por Pierce y Dewey que, a diferencia del Arielismo, que agotó rápidamente sus posibilidades de recepción y reproducción, no ha dejado de interesar a académicos e intelectuales de todo el mundo. El objetivo de este texto es demostrar que hay similitudes entre ambas formas de pensamiento y que el Pragmatismo, tan desconocido y vilipendiado en la América hispana por ser aparentemente una ideología del Imperio y del norte, es un interlocutor perfecto para iniciar un diálogo transcultural en el continente.

Palabras clave: Pragmatismo; Arielismo; América; Diálogo transcultural. 


\section{Introducción}

¿Es posible comparar lo que hasta ahora se ha olvidado de comparar suficientemente? Según el Diccionario Real de la Lengua Española (2001) la palabra comparar proviene del latín comparāre y significa "Fijar la atención en dos o más objetos para descubrir sus relaciones o estimar sus diferencias o semejanza". Si partimos de este punto reconocido por todos con respecto al término comparar, quisiera acentuar en este texto los verbos "descubrir" y "estimar" para comparar dos textos, el Ariel (1900) del uruguayo José Enrique Rodó y el Pragmatismo (1907) del norteamericano William James, textos que se articulan en dos lenguas, el español y el inglés, en dos masas continentales "opuestas" y en dos tradiciones intelectuales, culturales y religiosas “diferentes”, la latina y la nórdica, la católica y la protestante. Pero la pregunta es la siguiente: ¿qué tan diferentes en verdad son esas tradiciones o al menos esos dos textos fundacionales? Al considerar que son textos fundacionales nos referimos a que ambos textos fundan tradiciones intelectuales que aquí designaría como transculturales, extraeuropeas y periféricas, es decir, con Rodó se funda lo que se conoce como el arielismo y con James lo que se conoce como pragmatismo, aunque, leyendo a Arturo Ardao (1956), se puede sospechar que Rodó debió haber conocido los textos de James y Berson, una sospecha que amerita ser seguida de más cerca en próximos estudios.

El Ariel de Rodó y el Pragmatismo de James son textos que se elaboran a este lado de la orilla del Atlántico. Esto sería en primer lugar un punto en común, aparte de la matriz humanística que le da sentido a ambos textos, pues son elaboraciones dirigidas para dar sentido y transformar la práctica de lo que tradicionalmente se conoce como el Hombre, construcción del humanismo inscrito en la historia de las sociedades y las disciplinas (Foucault 1966). Es de aquí entonces que se deriva la siguiente pregunta: ¿Cómo responden estos dos textos a los retos de esta tercera fase de la modernidad ${ }^{1}$, especialmente, la relación de la Verdad con lo la Vida y lo Absoluto? Son textos que dialogan con toda la tradición intelectual de Occidente desde el platonismo, el cristianismo e, incluso, con la ciencia, entendido desde su perspectiva filosófica. Si bien el Ariel de Rodó, a diferencia del Pragmatismo de James, no fundó ninguna escuela filosófica, no dejó de ser influyente aquel texto por generaciones enteras de latinoamericanos en el orden de las ideas culturales, políticas y filosóficas. Y la pregunta es por qué no fundó una escuela de pensamiento (aunque no se puede negar todavía cierta presencia), a pesar que tuvo todos los elementos para que pudiera hacerlo. Hay que pensar, por ejemplo, en el Hombre Mediocre (1913/2000) de José Ingenieros y en los filósofos latinoamericanistas que ven en el Ariel un texto fundador. Pero, ¿por qué el arielismo agotó aparentemente sus propias posibilidades de un discurso transgeneracional? En este sentido, el texto de James sí fundó una escuela de pensamiento que ha

\footnotetext{
${ }^{1}$ Según el romanista Ette la primera fase se inicia con el descubrimento de América por Cristóbal Colón en 1492 ; la segunda a partir de la segunda mitad del siglo 18 que determina no solo el dominio cartográfico de la tierra sino también el colonialismo europeo, la tercera fase se caracteriza por la participación creciente de los Estados Unidos y, sobre todo, por la racionalización de todas las facetas de la vida determinada por el cambio significativo del factor tiempo; la cuarta fase se inicia en el último tercio del siglo XX caracterizada actualmente por eine weltweite vernetzung (2002: 27). En efecto, yo le agregaría a esta cuarta fase el hecho histórico, económico y cultural que significa el gradual desplazamiento de las relaciones de poder del mundo del Atlántico al mundo del Pacífico, China, India, y los países del sudeste asiático.
} 
Invest. pens. crit.

Vol. 3, No. 3, septiembre-diciembre 2015

pp. $62-73$

tenido como contemporáneos y seguidores a Pierce, Dewey, Habermas y Rorty, todos influyentes en ambas orillas del Atlántico y del mundo. En fin, aquí nos interesa poner a dialogar transculturalmente estos dos textos clásicos americanos, porque es una problemática no explorada aún en los estudios contemporáneos de historia intelectual en las Américas, aunque hay un excepcional precedente en el texto de Patrick Romanel (1954), donde se compara el vitalismo de Ortega (quien era el puente de la filosofía alemana) con el pragmatismo. Con este estudio, en efecto, no pretendemos reafirmar los tópicos tradicionales que separan ambas tradiciones intelectuales, pues lo que nos interesa es preguntarnos si hay posiblemente puentes de comunicación y puntos comunes que pueden ser más comunes de lo que uno puede imaginarse entre ambos textos que se articulan en espacios y redes intelectuales diferentes.

\section{El maniqueísmo cultural y el depósito romántico del Ariel}

En una antología no ya tan reciente elaborada por el mexicano Leopoldo Zea y Hernán Taboada sobre los cien años de haberse publicado el Ariel, éstos se hacen la pregunta sobre la actualidad de este libro en el tiempo de la globalización y llegan a la conclusión de que el Ariel "se presenta como una extraordinaria profecía de nuestro tiempo" (2002:5), por todos los tratados e impulsos de asociación y colaboración económica que hay en la América Latina. Pero, en efecto, lo que resalta de esta antología, compuesta por muy buenos trabajos académicos, es que no hay uno sólo que se dedique a explorar la relación que puede haber entre las tradiciones intelectuales de las Américas en general y, mucho menos, entre el arielismo y el pragmatismo. Ciertamente no hay citas o referencias mutuas de ambos autores, aparte de la sospecha de que Rodó debió por lo menos haber escuchado los nombres tanto de James como de Berson, como lo sugiere Ardao (1956), y de que ciertamente entre el pragmatismo de un James y la filosofía de principios del siglo XX en Uruguay-representada especialmente por Vaz Ferreira y Rodó-existía "una forma de síntesis entre el positivismo ciencista y el espiritualismo metafísico, centrada en una radical exploración de la experiencia desde nuevos ángulos de visión” (22).

Esta pequeña cita de Ardao es una línea de análisis que no se continuó posteriormente (sobre) los estudios y textos filosóficos de América Latina muy preocupados por encontrar una propia identidad cultural de pensamiento desde que Juan Bautista Alberdi se preguntara por una filosofía americana auténtica en el siglo XIX (Beorlegui, 2010). Este filón de Ardao, sin embargo, es realizado por Patrick Romanell (1954), por un único estudio que conozco (hasta ahora), que establece una relación entre la filosofía del pragmatismo y el vitalismo del español José Ortega y Gasset, quien había sido el puente de transmisión de la filosofía alemana con el mundo hispano y particularmente latinoamericano. No debemos olvidar que fue precisamente Ortega y Gasset quien defenestra el pragmatismo como filosofía al compararla incluso con la capacidad mental de un chimpancé al reducir esta corriente filosófica a puro instrumento: "El error del pragmatismo no radica en que considere las ideas como instrumentos, sino en que quiera reducir las cosas con que el hombre tiene que habérselas a lo perceptible y experimentable, lo que está a la mano y presente, el mineral, la planta, el animal y la estrella" (1981 [1931]: 155). No es lugar aquí para seguir esta discusión de Ortega (punto que ya realizó Romanell demostrando las afinidades de Ortega con el pragmatismo), porque la pregunta aquí es por qué nuestro 
interés por esta problemática sobre el arielismo y el pragmatismo. La respuesta se puede encontrar en que el Ariel es, posiblemente, la primera lectura tendenciosa (transcultural) de una cultura y corriente norteamericana de pensamiento que Rodó soslaya o desconoce por completo. Y de aquí se puede pensar que, con la recepción política y cultural del Ariel, comienza un gran malentendido cultural, un malentendido cuyo abono está depositado en lo más profundo de las narrativas culturales románticas del subcontinente, es decir, que a los latinoamericanos les pertenece una lengua, costumbres y religiones comunes que justifica su unidad y su común destino, posición tempranamente expresada por Simón Bolívar en su célebre Carta de Jamaica (1815/1999).

Rodó, por cierto, no menciona la palabra pragmatismo como adjetivo y, mucho menos, como filosofía (que puede inferirse por el desconocimiento del término para designar esta corriente), pero sí utilitarismo, cuando dice: "la concepción utilitaria, por lo cual nuestra actividad, toda entera, se orienta en relación a la inmediata finalidad del interés" (1900:15). Él asocia inmediatamente utilitarismo a interés, equivalentes en un mismo paisaje de representación, sin citar a nadie al respecto que confirme o rechace esta afirmación. Sin embargo, aquí uno se pregunta si, en verdad, el polígrafo uruguayo, quien además escribiera el Ariel como una reacción a la emergencia cultural, económica y política de los Estados Unidos de América en el globo, después de la pérdida definitiva del imperio español de sus últimas colonias en 1898, no tuvo jamás conocimiento de los pensadores ingleses, quienes concebían el utilitarismo como la prolongación de la postura epicúrea frente al mundo con el cual no el interés estaba en el centro de sus preocupaciones, pero sí la felicidad como punto central de sus reflexiones éticas. Es difícil creerlo y uno está más tentado a pensar que Rodó (maniqueísticamente) trastocó el sentido del utilitarismo como filosofía de vida. En efecto, el utilitarismo es fundado por los ingleses Jeremy Bentham y su seguidor más conspicuo, John Stuart Mill James dedica su libro Pragmatismo a este último), quien define el utilitarismo de acuerdo con Bentham como the Greatest Happiness Principle [El Principio más grande de Felicidad], así: "holds that actions are right in proportion as they tend to promote happiness, wrong as they tend to produce the reverse of happiness" (sn) [sostiene que acciones son ciertas en proporción a la felicidad que provocan y falsas en proporción a al reverso de la felicidad].

El principio de utilidad es evitar el dolor que impide la consecución de la felicidad y este principio ético no significa que toda acción en busca de la felicidad individual y colectiva es moral y éticamente aceptable, porque basándose en la doctrina cristiana Stuart Mill llega a afirmar lo siguiente: "in the golden rule of Jesus of Nazareth, we read the complete spirit of the ethics of utility. To do as one would be done by, and to love one's neighbour as oneself, constitute the ideal perfection of utilitarian morality" (sn) [En la regla de oro de Jesús de Nazareth leemos el completo espíritu de la utilidad. Tratar como nos gustaría que nos trataran, amar al vecino como nos gustaría que nos amaran, constituye el ideal de perfección de la moral utilitaria]. Este principio no coincide con el concepto de utilidad utilizado por Rodó, que es una derivación empobrecida y vulgar del sistema filosófico humanista del utilitarismo, una derivación que el mismo utilitarismo supo afrontar en su tiempo al mencionar, por ejemplo, que si bien no había ningún teoría del utilitarismo que había sobrevalorado las cosas del 
Invest. pens. crit.

Vol. 3, No. 3, septiembre-diciembre 2015

pp. $62-73$

espíritu sobre el cuerpo, sí había un consenso en que las cosas del espíritu gozaban de mayor permanencia y calidad que las cosas del cuerpo. De hecho, Rodó sabía (pues era lo más elemental) que el utilitarismo se había originado en Inglaterra como lo muestra la siguiente cita: " — Si ha podido decirse del utilitarismo que es el verbo del espíritu inglés, los Estados Unidos pueden ser considerados la encarnación del verbo utilitario" (22).

Pero lo que sí sorprende es el giro tendencioso y maniqueísta de presentar el utilitarismo de forma tan simplificada, gesto que en verdad sólo es posible hacerlo por premeditación y no por ignorancia. Aparte del efecto ideológico-cultural de este maniqueísmo cultural, una maniobra que le dio a generaciones de lectores latinoamericanos un instrumento torcido de representación cultural sobre el norte e, incluso, sobre la llamada cultura latina, lo que se presentó aquí fue un verdadero corte que tuvo consecuencias funestas para generaciones enteras que leyeron este texto especialmente en la idea de la cultura del norte. Aunque hay que advertir que, como afirma Carlos Real de Azua en su clásico prólogo del Ariel en la Biblioteca Ayacucho (1976/1990), el texto de Rodó no era un texto para "ir contra la corriente", y el pasaje que se dedica a la "nordomanía" ocupa un tercio del texto y es el que le ha conferido ese "dilatado eco" (XXVII). Ciertamente, no se trata de juzgar el texto de acuerdo a las condiciones de hoy, pues el mismo "se hizo eco de las necesidades de su tiempo" (Andueza, 2002: 107), pero uno no se deja de preguntar cómo fue la recepción de aquellos lectores cuando leen de Rodo sobre el norte, lo siguiente:

Su cultura, que está lejos de ser refinada ni espiritual, tiene una eficacia admirable siempre que se dirige prácticamente a realizar una finalidad inmediata. No han incorporado a las adquisiciones de la ciencia una sola ley general, un solo principio (24).

Pero en verdad nos equivocamos si pensamos que fue por Rodó que los lectores tuvieron esa versión tan simplificada del norte. Ese nudo temático del texto, como lo hace saber Real de Azua, respondía a las expectativas del lector de la época, era una articulación de ya consabidas fórmulas de recitación sobre el norte y lo verdaderamente interesante es la poca libertad que pudo haber tenido el polígrafo para explayarse sobre el norte. Este nudo del texto respondía a las expectativas del público receptor de la época. Esto no quita que Rodó no recupere la fuerza, el sentido práctico de las cosas, la voluntad y la destreza de los del norte. Y de aquí entonces conocemos la tan célebre frase que dice: "Y por mi parte, ya veis que, aunque no les amo, les admiro" (24). Mucho ya se ha escrito sobre el Ariel, pero muy poco se ha dicho sobre estas simplificaciones culturales del autor uruguayo (con gran probabilidad expectativas de la recepción), porque nadie con un poco de sensatez aceptaría que los del norte, los anglosajones, no tienen cultura elevada, un ideal, que no poseen un solo principio, una ley general, pues sólo habría que pensar en el primer principio salido del país del utilitarismo, el Habeas Corpus, el primer paso dado en la trayectoria frágil y accidentada del estado de derecho y las democracias contemporáneas, liberales y abiertas. Lo que sí es interesante constatar es la manera curiosa, contradictoria, en que Rodó a pesar de la simplificación esperada por la recepción, trata ciertamente de ver/escribir lo que no se espera por esa recepción al señalar que "El espíritu inglés, bajo la áspera corteza de 
utilitarismo, bajo la indiferencia mercantil, bajo la severidad puritana, esconde, a no dudarlo, una virtualidad poética escogida...” (26). Y más adelante afirma con respecto al utilitarismo, después de hablarnos de la democracia del número, del cosmopolitismo (el peligro de la inmigración), de la falta de contenido ideal de la cultura anglosajona, que "no es mi propósito afirmar que la obra realizada por él haya de ser enteramente perdida con relación a los que podríamos llamar los intereses del alma” (29).

En fin, él no cierra la posibilidad de que los anglosajones se levantan sobre la cultura material, sin ideales, más allá del interés práctico inmediato, una posición que no termina de romper las expectativas con respecto a ese Ariel que es levantado como un paladín de la cultura latina en un continente que se sentía amenazado por su vecino del norte.

\section{E1 Interlocutor silenciado: el pragmatismo}

Rodó no menciona jamás la palabra pragmatismo para referirse a la filosofía que se considera heredera del utilitarismo, pues como ya se ha mencionado en la primera parte, James le dedica su libro a Stuart Mill, nombre que Rodó menciona en su Ariel para referirse tan sólo a la religiosidad de los anglosajones, específicamente los norteamericanos cuya moral utilitarista, según él, no tenía todavía la autoridad religiosa como lo quería Stuart Mill. Pero de aquí no se lee más con respecto a al utilitarismo y, por otra parte, es difícil imaginarse que James tenía conocimiento de Rodó y de su libro Ariel. De hecho, el tex to Pragmatismo de James es el conjunto de una serie de conferencias que el autor norteamericano preparó en la Columbia University de New York entre 1906 y 1907. Es un texto que posee el sugerente subtítulo de "un nuevo nombre para un pensar antiguo", porque ve hasta en Sócrates uno de sus predecesores en el método, la indagación inductiva, y comparte además junto con el Ariel el punto de que es dirigido a un público joven, estudiante, receptivo a inquietudes de nuevos pensamientos e ideas. Aquí, por cierto, no hay un Próspero, un sabio, que anuncia su Ariel al mundo, pero si tomamos a James como el Próspero mismo, podría considerarse que el texto mismo, El Pragmatismo, es el Ariel de esa filosofía, que recupera al igual que el Ariel de Rodó, a Cristo (especialmente la máxima ética de tratar a los demás como nos gustarían que nos trataran, punto que lo plantea también Stuart Mill), a la antigüedad clásica, la importancia de los valores (entendido como respuesta al vacío de creencias) y el ideal, y que mira con escepticismo y distancia toda verdad absoluta que impida la indagación libre, experimental y científica del mundo. Por lo tanto, podría afirmarse que, en más de un de un punto, James estaría de acuerdo con Rodó (evidentemente saltando sobre el nudo panfletario contra la simplificación del utilitarismo), particularmente con aquella frase de Rodó que ilustra con mayor nitidez la idea del Ariel:

Basta que el pensamiento insista en ser, - en demostrar que existe, con la demostración que daba Diógenes del movimiento, - para que su dilatación sea ineluctable y para que su triunfo sea seguro (32).

En efecto, Diógenes, un filósofo de la antigüedad a quien el mismo Nietzsche pagó un gran tributo al rescatarlo en su obra, era contemporáneo de Platón. Y a diferencia de éste no partía del hecho de que la Ideas fueran absolutas y eternas, sino que pertenecían al caudaloso devenir de la experiencia práctica 
Invest. pens. crit.

Vol. 3, No. 3, septiembre-diciembre 2015

pp. $62-73$

de la vida, del movimiento que todo lo transforma. Si Platón partía de la Idea para definir el mundo moral, Diógenes partía de este movimiento que, como lo reconoce James, va más allá del racionalista que es de una "conflexión doctrinaria y autoritaria” (172):

En cambio un pragmatista radical es una criatura anarquista y feliz. Si tuviera que vivir en un tonel como Diógenes, no le importaría si los aros estuviesen flojos, y los listones dejaran entrar el sol (172).

Esta afirmación de James, que es muy sucinta con respecto a Diógenes (como la de Nietzsche y Rodó), es de suma importancia porque son conscientes que en la antigüedad hay un universo no-platónico que da espacio al movimiento, al infinito y la interminable búsqueda. Es interesante observar que, en el caso de Rodó, esta metáfora del movimiento y de la acción está proyectada en que "Grecia hizo grandes cosas porque tuvo, de la juventud, la alegría, que es el ambiente de la acción, y el entusiasmo, que es la palanca omnipotente" (4). Con otra cosa no pudo estar de acuerdo James, particularmente con esa figura de Diógenes, "una criatura anarquista y feliz", y que en Rodó se proyecta en esa juventud que debería estar entregada a la acción. Si bien no es fácil definir el pensamiento de Rodó por su “diversidad de vertientes” (Gastelumendi Florentino, 2002: 51), sí se puede pensar que Rodó no maneja un concepto platónico de la Idea pues menciona la necesidad de un "pensamiento emancipado de todo innoble jugo" (1900: 9) y denuncia "los resultados del espíritu estrecho y la cultura unilateral" y "la tiranía de un objetivo único e interesado" (8), donde en el espíritu cabría la pasión y el interés, el sentimiento y la razón, es decir, en Rodó al igual que en James lo que hay que liberar es al espíritu de las determinaciones absolutas que impiden el movimiento de las ideas y buscar la validación de la verdad ya sea por su utilidad o por la acción:

El pragmatismo, por devoto que sea a los hechos, no tiene tal tendencia materialista como el empirismo ordinario. Además, no tiene objeción alguna para la realización de abstracciones, en tanto os alleguéis a las particularidades con su ayuda, y ellos actualmente os llevan a alguna parte. No interesado en ninguna conclusión sino en aquellas en las cuales nuestra mente y experiencia realiza juntas, no tiene a-priori prejuicios en contra de la teología. Si las ideas teológicas prueban tener un valor para la vida concreta, serán verdad, para el pragmatismo en el sentido de su extraordinaria eficacia (65).

El pragmatismo se distancia tanto del racionalismo, que pretende atrapar la vida, la verdad, el movimiento, en las categorías absolutas de la idea, como de los simples hechos, el empirismo que ahoga toda abstracción. No hay en James, como pragmatista que era, el más mínimo desprecio por las cosas del espíritu y, mucho menos, por la teología, pues el punto central era la pregunta sobre su eficacia para los seres humanos en su vida práctica. Su pragmatismo era el equilibrio continuo de la idea y la materia, de la reflexión y la acción, de lo uno y lo plural, de la fe y la ciencia, del individuo y el colectivo. Para James, que era un 'pragmatista pluralista', la verdad no era la verdad absoluta, pero sí el sentido y la pregunta de si esa verdad corresponde la vida de los seres humanos. Él no discutía la justeza innata o no de la verdad, sino que cada esfera tenía un concepto de la verdad que funcionaba y le daba sentido y veracidad a quienes la proponían: 
El sentido común es mejor para una esfera de la vida, la ciencia para otra, la crítica filosófica para una tercera: pero cuál sea absolutamente verdadera, solo Dios sabe (132).

La pregunta pragmática para James es que la verdad es un proceso, es una circunstancia, es un evento y una posibilidad de verificación. No se trata, por supuesto, en decir que este concepto de verdad es compartido por Rodó, pero, sin duda, James habría estado completamente de acuerdo con la siguiente afirmación que inaugura el segundo capítulo del Ariel:

La divergencia de las vocaciones personales imprimirá diversos sentidos a vuestra actividad, y hará predominar una disposición, una aptitud determinada, en el espíritu de cada uno de vosotros. - Los unos seréis hombres de ciencia; los otros seréis hombres de arte; los otros seréis hombres de acción. - Pero por encima de los afectos que hayan de vincularos individualmente a distintas aplicaciones y distintos modos de la vida, debe velar, en lo íntimo de vuestra alma, la conciencia de la unidad fundamental de nuestra naturaleza, que exige que cada individuo humano sea, ante todo y sobre toda otra cosa, un ejemplar no mutilado de la humanidad, en el que ninguna noble facultad del espíritu quede obliterada y ningún alto interés de todos pierda su virtud comunicativa (7).

De esta cita de Rodó es legítimo preguntarse sobre las afinidades de ambos a pesar de pertenecer a lenguas y "culturas" diferentes. Me atrevería incluso a pensar en el pragmatismo de Rodó, silenciado o invisibilizado, un pragmatismo que sin duda alguna transpira entre los poros de este texto híbrido e imbricado, complejo y diversificado que es el Ariel. Esta mirada permitiría descubrir una línea que nos llevaría más allá del capítulo panfletario, sectario y excluyente del capítulo tercero del Ariel, donde la cultura latina se establece en un paisaje lleno de trincheras culturales. Levantar la mirada sobre ese capítulo implicaría establecer puentes transculturales que, si uno queda atrapado en aquel capítulo, no da cuenta de la circulación transatlántica de ideas que debió de existir y existía para principios del siglo XX. Es así que si queremos ganar una nueva mirada para el Ariel, queda entonces ver más allá de la esfera política-cultura del capítulo tercero, pues aquí se romantizó conservadoramente a la cultura latina, es decir, que a una raza le pertenece una cultura. Y de aquí toma sentido compararlo con el pragmatismo, porque esta corriente filosófica reclama para sí la tradición de toda la cultura occidental desde los griegos antiguos, pero no para fundamentar la herencia o la tradición de una raza, pero sí para fundamentar una filosofía que pretende en palabras de James dar "la espalda resueltamente y de una vez por todas a una cantidad de hábitos inveterados y caros a filósofos profesionales. Se aleja de la abstracción y la insuficiencia, de las soluciones verbales, de las malas razones a priori, de los principios rígidos, sistemas cerrados, y pretendidos absolutos y principios” (53).

Lo que salta a la vista entonces es que a diferencia del Ariel del Rodó, el pragmatismo con James no recurre a la raza - o a la cultura anglosajona - para legitimar su posición filosófica, punto este que coincidiría con la observación de Jean Franco con respecto a las Vanguardias en el siglo XX: que, mientras las Vanguardias europeas dan cuenta de movimientos estrictamente artísticos como el su- 
Invest. pens. crit.

Vol. 3, No. 3, septiembre-diciembre 2015

pp. $62-73$

rrealismo, cubismo o dadaísmo, etc., en América Latina y el Caribe están conectadas con discursividades raciales como mulatismo, negritud o indigenismo (1985). En este sentido, el Ariel de Rodó al ser romantizado racialmente (por el mismo autor) se inscribe en esta tradición intelectual de usurpar el depósito greco-romano como si el mismo fuese privilegio prerrogativo de alguna cultura o raza en particular.

\section{Un contrapunto Americano filosófico}

Tanto James como Rodó tenían en mente el ejemplo griego para sus textos. Lo que les interesaba era ir al encuentro de la armonía: "Atenas supo engrandecer a la vez el sentido de lo ideal y el de lo real, la razón y el instinto, las fuerzas del espíritu v las del cuerpo” (1900: 8). Esto, por cierto, pudo haberlo escrito perfectamente James, es más, éste va al encuentro del tan caro Ideal de Rodó, de su espontaneidad, del ideal heroico característico de la juventud cuando dice al respecto: "Necesitáis un sistema que combine ambas cosas, la lealtad cientista a los hechos y buena voluntad de tomar cuenta de ellos: el espíritu de adaptación y acomodación, en una palabra, pero también la añeja confianza en los valores humanos y la espontaneidad resultante, ya sea de tipo religioso o heroico" (1907: 35). Estas coordenadas compartidas por James, es decir, la articulación del universo griego en su filosofía del pragmatismo no es posible completarlo sin su relación con el arte y, especialmente, con la estética. No hubo nada que le fuese extraño a la filosofía clásica del pragmatismo, ni a Pierce, quien escribió precisamente la primera obra semiológica sobre el lenguaje, y quien introdujo, según James, por primera vez el pragmatismo (derivación de la palabra griega pragma) “en la filosofía (...) en 1878” (50), y mucho menos a John Dewey que con su texto, El arte como experiencia (1934/1949]), tiene el proyecto de explicar el arte como experiencia, es decir, que la experiencia es el denominador común del arte y, por lo tanto, afirma, lo siguiente: "todas las oposiciones de mente y cuerpo, de materia y alma, espíritu y carne, tienen su origen fundamentalmente en el temor de lo que la vida pueda traer" (22). En este encuentro con la vida no hay nada que tampoco le pueda ser extraño a Rodó, especialmente cuando se trata de romper la oposición clásica, base de todas las oposiciones que incluso atraviesa lo que se entiende como "arte popular y culto", punto que ya hoy no tiene prácticamente ninguna validez, pero lo que sí tiene contemporaneidad es el acento que se le da a volver a considerar las ciencias humanas y en particular la literatura como experiencias de vida en el más amplio sentido de la palabra: "Y sin embargo, entre todos los elementos de educación humana que pueden contribuir a formar un amplio y noble concepto de la vida, ninguno justificaría más que el arte un interés universal, porque ninguno encierra, - según la tesis desenvuelta en elocuentes páginas de Schiller, — la virtualidad de una cultura más extensa y completa, en el sentido de prestarse a un acordado estímulo de todas las facultades del alma" (11).

Por supuesto, habría que investigar mucho más esta relación entre Rodó y James que, más que un asunto de individuos o autores, pertenece posiblemente a lo que se conoce en alemán como el Zeitgeist [espíritu del tiempo], una sensibilidad compartida de temas y preocupaciones de este lado del Atlántico, más en un momento de intercambios transatlánticos en todas las esferas del conocimiento. La pregunta aquí abierta es por qué precisamente en las Américas se da este impulso por descubrir la vida, 
ir más allá de la separación ontológica entre el cuerpo y el alma (y en términos más específicos ir más allá de la separación del conocimiento). ¿Por qué aquí tomó forma esa búsqueda común griega y cristiana, Diógenes y Cristo? ¿Acaso aquí el proceso de Ilustración no se había abierto paso? En ambos mundos-el anglosajón y el hispano-había que construir naciones, culturas, sociedades y mundo intelectuales. Había que trabajar con todas las corrientes a la disposición, aunque en el Ariel a base de excluir y segregar a los del norte, la "nordomanía", como la llamaba Rodó. Lo cierto es que hay es una línea que ha pasado desapercibida. No hay un puente transcontinental en este aspecto que ponga a dialogar textos y filosofías. A esto hay que agregar que no existe un estudio sobre el pragmatismo en las Américas y, especialmente, en la América Latina, a pesar que en el primer tercio del siglo XX el pragmatismo tuvo su presencia como filosofía educativa en Cuba, Puerto Rico y Panamá. Y lo que fue una articulación cultural-filosófico de las Américas al momento de crearse el Ateneo de México, centro del encuentro de los filósofos jóvenes americanos (Rafael Reyes, José Vasconcelos, etc.) con José Gaos y la enorme sombra de Ortega y Gasset, quien fue el puente filosófico entre Alemania y las Américas por su Revista de Occidente, definió una trayectoria filosófica romantizada de fuerte impacto en la América Latina orientada a crear culturas e identidades propias, impulso que es posible perseguirlo hoy día en la Teología de la Liberación y la Teoría de la Decolonialidad, no por la continuidad de temas y preocupaciones, pero sí por el impulso de crear lugares propios de enunciación discursiva, ya no orientadas a crear naciones e identidades, pero sí articulaciones transnacionales que impelen a los excluidos y marginales (negros, pobres, indígenas), figuras no atendidas en el Ariel del Rodó, por ejemplo.

El diálogo transcultural ha quedado completamente suspendido, ahogado, por décadas de desinterés mutuo, por lo menos en el área de la reflexión y la filosofía en este punto. Hoy día el arielismo es historia como movimiento (y en verdad dudo si lo hubo alguna vez, aparte de la amplia receptividad que tuvo por varias generaciones de lectores), no forma parte de ninguna discursividad académica o extra-académica, y la razón de esto es posiblemente, como lo afirma Methol Ferré de que "el error básico de Rodo es que escinde al Ariel del poder" (2002: 38). En este sentido, cierto, James al definir el pragmatismo lo orienta también (explícitamente) hacia el poder, pertenece a la amplia constelación de lo que es el pragmatismo, es decir, cuando habla de la acción no es un acto vacío de poder, lo lleva implícito en sí, el poder del pragmatismo como método, como "temperamento" de esta filosofía que propone el "pluralismo", el asalto de todo dogma que impide el movimiento y que se ha instalado como una corriente filosófica con múltiples variantes. En cambio, del arielismo de Rodo queda sólo un texto, posiblemente cercenado y olvidado por haber sido recitado y secuestrado políticamente en su capítulo tercero, porque él mismo además fue su mejor promotor, perdiendo así el texto todo su poder interior de transformación, de dinamismo frente a la vida, que implica su Ariel, una especie de Zaratustra que terminó perdiéndose en el remolino del tiempo, pero que todavía vive (o sobrevive) en las discursividades culturales de nuestros intelectuales. 
Invest. pens. crit.

Vol. 3, No. 3, septiembre-diciembre 2015

pp. $62-73$

\section{Conclusión}

Esta comparación entre Rodó y James muestra que es posible conectar y comparar textos que tradicionalmente se ha visto separados en las Américas. Es un diálogo necesario, transcultural y transtextual, porque son discursividades que se han dado a este lado del lado del Atlántico, el arielismo y el pragmatismo, y que han determinado generaciones de lectores americanos del continente. Ambos textos, ciertamente, dialogan con toda la tradición occidental de su momento de la cual se siente herederos, recitadores e impulsadores con la misión de fundar una moral y filosofía nueva para un continente a la búsqueda de su emancipación y libertad humana, cultural y social.

\section{Referencias}

Andueza, M. (2002). Los hijos de Ariel. En L. Zea y H. Taboada (comps.), Arielismo y Globalización (pp. 107-114). México: Fondo de Cultura Económica.

Ardao, A. (1956). La filosofía del Uruguay del siglo XX. México: Fondo de Cultura Económica.

Beorlegui, C. (2010). Historia del pensamiento filosófico latinoamericano (una búsqueda incesante de la identidad). Bilbao, España: Universidad de Deusto.

Bolívar, S. (1999). Carta de Jamaica. Recuperado de www.elaleph.com. (Trabajo original publicado en 1815).

Dewey, J. (1949). El arte como experiencia. México-Buenos Aires: Fondo de Cultura Económica. (Trabajo original publicado en 1934)

Ette, O. (2002). Weltbewutßein. Alexander von Humboldt und das unvollendete Projekt einer anderen Moderne. Weilerswist, Alemania: Velbrück Wissenschaft.

Ferré, A. M. (2002). Del arielismo al Mercosur. En L. Zea y H. Taboada (comps.), Arielismo y Globalización (pp.33-40). México: Fondo de Cultura Económica

Foucault, M. (1966). Le mots et les chose (une archéologie de sciences humaines). Paris, Francia: Gallimard.

Franco, Jean. 1985. La cultura moderna en América Latina. México: Grijalbo.

Gastelumendi Fiorentino, A. M. (2002). “La razón rodoniana”. En L. Zea y H. Taboada (comps.), Arielismo y Globalización (pp.51-60). México: Fondo de Cultura Económica

Ingenieros, J. (2000). El Hombre Mediocre. Recuperado de https://www.elaleph.com. (Trabajo original publicado en 1913).

James, W. (1947). El Pragmatismo. Buenos Aires: Editorial AmericaLee. (Trabajo original publicado en 1945) 
Ortega y Gasset, J. (1981). Meditación del pueblo joven y otros ensayos sobre América. Madrid, España: Alianza Editorial.

Real Academia Española [RAE]. (2001). Comparar. En Diccionario de la lengua española (22.a ed.). Disponible en http://lema.rae.es/drae/?val=comparar

Rodó, J. E. (1900). El Ariel. Disponible en Katariche http://www.scribd.com/people/view/3502992-jorge.

Rodó, J. E. (1990). Ariel-Motivos de Proteo. Prólogo de Carlos Real de Aqua. Caracas, Venezuela: Biblioteca Ayacucho. (Trabajo original publicado en 1976).

Romanell, P. (1954). La formación de la mentalidad mexicana (panorama actual de la filosofía en México 19101950) (E. O’Gorman, Trad.). México: Fondo de Cultura Económica.

Stuart Mill, J. (2004). The utilitarianism. Producido por Julie Barkley y Garrett Alley. Disponible en http://www.gutenberg.net. (Trabajo original publicado en 1879).

Zea, L. y Taboada H. (comps.). (2002). Arielismo y Globalización. México: Fondo de Cultura Económica. 